\title{
How to support decision making of local government in prioritising policy menu responding to citizens' views: An exploratory study of text mining approach to attain cognitive map based on citizen survey data
}

\author{
Hiroko Oe $^{1}$, Yasuyuki Yamaoka ${ }^{2}$, and Eizo Hideshima ${ }^{3}$ \\ ${ }^{1}$ The Business School, Bournemouth University, UK \\ hoe@bourunemouth.ac.ul. \\ ${ }^{2}$ Comparison Region Research Center, The Open University, Japan \\ monthill@jj7.so-net.ne.jp. \\ ${ }^{3}$ Nagoya Institute of Technology, Japan \\ hideshima.eizo@nitech.ac.jp.
}

\begin{abstract}
It has been on the political agenda for the local governments how to satisfy their citizens to enhance their commitment and contribution to the communities. Especially in this ageing population era with tight fiscal conditions, it is essential for the government to know the prioritised policy menu in realising citizen satisfaction. This study aims to explore an applicable system based on citizen survey result. In our study, following literature review, we conducted focus group discussions to explore citizens' willingness to participate in local policy design, which leads us to be convinced that some activated citizens are supportive to the local governmental policy decision. Based on this qualitative result, we tried to make a cognitive map which indicated which policy fields are prioritised by citizens. Throughout this procedure, we validate the feasible practice to support local governmental decision making based on the result of citizen survey.
\end{abstract}

Keywords: local government, citizen perception, citizen survey, text mining, cognitive map

\section{Introduction}

\subsection{Background}

Japan has been suffering from various political problems merged from depopulation, imbalanced bipolarisation, old deterioration of social infrastructure, aggravation of regional financial difficulties and other factors [1]. Especially the social infrastructure maintenance and other long-term social policy require huge amount of budget and its period of gestation is longer, hence the local governments should put priorities in policy agenda.

Ministry of Land, Infrastructure, Transport and Tourism [2] provided some suggestions for the local governments and relevant stakeholders to combine their 
resources to check the policy framework so that they can maintain sustainability in designing their communities, by enhancing citizens participation and contribution, responding to this, many governments have been trying to gather citizens voices via surveys to re-design their community managerial schemes. But still they seem to have difficulties in finding the antecedent factors in determining citizen satisfaction which could lead to their participation and contribution to the communities. This means that the budget expended to conduct citizen survey is not utilised which has been on the policy agenda for a while $[3,4]$.

The discussion which policies and public activities by the local governments are appreciated by the citizens and leads to the citizen satisfaction is missing $[4,5,6,7,8]$. Indeed quite a few local councils re interested in conducting citizen survey, however the best practice how to reflect its result in the real policy making phase are still under experiment $[4,5,9,10,11]$. This is the background for this study. Hence, it has been maneuvered to support governmental decision making through data mining, which indicates more effort in realising its favourable and effective outcome $[12,13,14,15$, $16,17,18]$.

\subsection{Aim and Objectives of this Study}

The aim of this study is to find the feasible procedure for the local governmental decision making in prioritising policy menu based on citizen survey data. Hence, we, in the first place, investigate the citizens' willingness to support their local government as active participants by conducting focus group discussion (FGD) to depict essential views from citizen's intention to participate and contribute to their local governmental policy making. Based on the essence from FGDs, we build a cognitive map from the data of citizen survey to indicate potential pathway in prioritising policy menu. A cognitive map is built using a commercial text mining system which is affordable for the public sector rather than implementing a gigantic data analytical software. We expect from this reasonably designed two steps of data analysis to propose a realistic action plan for the local government to utilise the result of citizen survey, which means that the budget for the survey itself could be effectively valued which is another aspect for the good practice of local government $[20,21]$.

Hence, our objectives are:

a) to explore the citizen's perceptions towards local government activities,

b) to attain a cognitive map based on commercial text mining system,

c) to evaluate the effectiveness of the b) as a data mining to support local governments' decision making,

d) to present good practical implication for the local governments who have been seeking the best way in decision making of prioritised policy menu. 


\section{Literature Review}

\subsection{Overall discussion}

Crowley and Coffey [22] pointed out that Bridgman and Davis [23] have argued that 'ideally government will have a well developed and widely distributed policy framework, setting out economic, social and environmental objectives', hence local governments should aim at reconnecting with community priorities and at redirecting macro-policy setting away from a preoccupation with economic priorities, respectively. Irimia [24] analyses the political framework and citizens satisfaction based on a socio-cultural perspective and found we can come closer to the intangible aspects and hidden antecedent factors realizing their satisfaction. Then next question should be how to prioritise policy menu among various dimensions of those. Also how to support the best decision making to satisfy citizens in maintain them loyal to the government has been on the agenda up today $[12,19]$.

\subsection{Satisfied citizens and positive support towards the local governments}

There are also discussions about citizens' psychological aspects also for the debate of their satisfaction. Cordes et.al. [25] investigate the application of contingent valuation in social capital, attachment value and rural development. Crawford et.al. [26] debate the need for the value of community participation [5, 25, 26, 27, 28, 29, 30, 31]. Robison and Flora [33] resent a social capital paradigm that includes social capital, socio-emotional goods, attachment values, networks, institutions and powers. Julian and Ross [34] explore infrastructure and functions to serve as a foundation for collaborative community problem solving. Yoshitake and Deguchi [35] analyse a Japanese case of the town planning in the depopulation era to indicate that the residents' community attachment and human encounters, mutual understanding and discreet leadership could be essential. They evaluate this aspect of citizens' perception as a positive inclination and supportiveness towards their own local government $[17,36]$.

Regarding citizen participation and their satisfaction, Bedford et.al. [37] debate the extent to which collaborative approaches to planning and decision making are capable of giving precedence to the concerns of the public or of promoting trust in local institutions, indicating that the possibility of new participation practices associated with the development control process to determine citizens satisfaction level. Noworól [38] contribute to an understanding of the influence of social capital on the contemporary community management, also Olsson [39] discuss why and how to lead local citizens and their values into account in urban management and planning. Similarly, Martin and Morehead [40] discuss the importance of civic governance and civic infrastructure, implying that civic engagement, inclusiveness, leadership, participation, community vision, diversity and networking as elements are fundamentals for the civic governance in realising citizens satisfaction. Perhaps we could name this 'civic infrastructure'. 


\subsection{Health and welfare policies and satisfaction in the ageing era}

Warburton et.al. [41] debate that effective policy responses to the ageing of the population are a priority area for government and non-government agencies, Williams and Pocock [42] also debate how to cope with population portfolio changes which had a major impact especially social policies such as health and welfare matters. It is inevitable for us to discuss health and welfare policies and citizen satisfaction in this ageing era [43, 44, 45]. Caldwell et.al. [44] indicate the concept of the ageing population is one that has generated much debate and discussion at global, national and local levels. Julian and Ross [34] also debate researchers should focus on problem solving in the health, education, and social services arenas. Mitchell and Shortell [46] introduce the concept 'community health partnerships' as voluntary collaborations of diverse community organisations in order to pursue a shared interest in improving community health. Here again we can see the area which citizens' views should be reflected to collaborate in choosing a good policy framework $[7,47,48]$.

\subsection{Social infrastructure improvement and its decision making}

Social infrastructure issues should be another factor influencing citizens' satisfactory level. Work, Patrick and Roseland [49] analyse the importance of developing community in the residential areas, indicating that specific physical and social infrastructure in the residential area and the workplace should be prioritised on the political agenda. Dabinett [50] analyse urban areas where we should pursue a range of regeneration policies. Marshall [51] shows how distinctive the UK context has become since the 1990s, with the new legislation emerging from the political economy of powerful infrastructure industries, interacting with the particular configuration of interests represented by the New Labour government. Similarly also in Australia, as McShane [36] debated the importance of a management of community infrastructure by local governments, coping with a shortfall to maintain ageing physical assets. However, the policy seems to rely on a model of local government as a service provider only that is inattentive to new interests in community building and governance and takes limited account of the wider social value of community facilities [29, 36, 45, 52]. This means that the issue how and to what extent local governments should implement its infrastructure refurbishment is on the policy agenda. Decision support procedure is required $[40,53]$.

\subsection{Environmental beautification}

The improvement of rural or city environment have been oriented toward raising the level of living standard for the citizens, since 1970's in Japan especially in Japan for local towns and cities after the high economic growth [54]. The economic growth caused some issues such as the surplus of farm products, the air and water pollutions, heavy traffics on roads, and nature destructions in rural areas $[54,55]$. The movement for beautification of city environment has risen since 1980, affected by the German movement to 'make our village beautiful' [54]. Then next question should be the 
factor of 'beautification' could enhance citizen's attachment or loyalty to their local area or not [56, 57]. Fransico [57] proves that willing to pay (WTP) for an improvement in urban aesthetic values are significant, even he indicates that WTP for urban aesthetic improvements increases more than proportionally as income rises, which implies that improving city aesthetics are valued by citizens. This debate is compatible with Shigeoka [54]'s argument that community aesthetics has developed to bring up the love for their own homeland.

\subsection{City buzz}

Age-friendly city components are presented by Kennedy [58], whereas he emphasises the importance of re-imagining city with aging-in-place communities should be vibrant enough to attract young people, while welcoming older people to stay in their same community for a lifetime. Ghahramanpouri et.al. identify contributing factors for urban social sustainability, indicating that town vibrancy could be the basis in the aging era. Similarly scholars debate the impact of city buzz and vibrancy as one of the factors to attract people to vitlise the relevant communities which could contribute to the sustainability of the area $[60,61,62]$.

There are several research and case studies to explore factors which could enhance the city attractiveness. They implied the importance of city buzz as an origin for the sustainability with loyal citizens to the area $[62,63,64,65,66,67,68]$. IN this context some scholars indicated the role of social entrepreneurs in the area to generate community associations and networking that could produces favourable social outcomes [69].

\subsection{Trust for local government}

Trust from citizens to the local government is critical for managerial flexibility and political accountability in the modern administrative state [30]. There is an accumulation of research focusing on the impact of trust which leads to good support for both central and local governmental activities and to enhance further citizen commitment and their public involvement [70, 71, 72, 73]. Moreover quite a few scholars have explored the impact of trust as an antecedent factor to influence citizen satisfaction towards their governments $[11,74,75]$.

\section{$2.8 \quad$ Research questions}

Following the literature review above, the research is designed to find out how citizens evaluate and perceive governmental policy making in their local government and to provide explanations of why they regard particular issues important in the context of their citizenship. To answer this question, we explore the citizens' willingness to participate and support their local governmental policy designing, which is going to be followed by the evaluation of the cognitive map attained from the citizen survey result. 


\section{$3 \quad$ Methodology}

This research is conducted based on two phases, both are qualitative approaches; FGD and cognitive mapping.

The academic interest in the decision-making processes is concerned with human behaviours. In this context, to understand what is happening, it is important to focus on meanings [76]. Focus groups were chosen as being an appropriate methods of eliciting meanings [77]. The method is also efficient, being capable of obtaining a good set of citizens' views in an efficient way. Inductive approaches were taken so that the views attained from FGD were those of the citizens who are willing to present their opinions in a supportive way, which are not determined by the prescriptive approaches that are conducted in positivist research [77].

Cognitive mapping is a qualitative technique designed to identify cause and effect as well as to explain causal links [77]. It is used to structure, analyse and make sense of problems [77]. There are a small number of computer programs that can be used to conduct this type of work. As our aim is to evaluate the applicability of supportive decision making software, so as a material for doing it, we conduct text mining based on a relevant commercialised software to attain a cognitive map of informants.

\subsection{FGD and data gathering}

18 citizens aged 35 and over volunteered to participate in our FGDs, they were divided into three groups and facilitated by one of the authors for active collaborative discussions. [77] presents the importance that researcher's notion of what a focus group is will influence the quality and therefore the utility of responses received, categorising in three types of focus groups which are phenomenological interactioncentred focus groups, clinical focus groups and exploratory research. An exploratory research being most common to examine a topic quickly and at low cost before conducting follow-up survey [77].

Participants to our FGD are diverse with regard to demographic characteristics, and they are asked to respond to three general questions:

- Are you willing to contribute to and support the policy making of your local government?

- What do you perceive the barriers to implement effective public participation?

- How can you evaluate the current citizen participation in prioritising the best portfolio of policy menu?

Followed by free conversation and discussion among the participants facilitated by the authors with a guidance from a perspectives how to support decision making with active citizens' supportive participation.

The discussions lasted for about two hours each group and were recorded and transcribed. In the first stage of the analysis, we coded the transcribed interviews and discussions individually, using a qualitative form of content analysis which was suggested by Corbin and Strauss [78]. In the second stage of analysis, we will put the data into the text mining system to obtain a cognitive mapping to create visualised categorical themes which should indicate citizens' perceptions for the prioritised policy menu. 


\subsection{Cognitive mapping of the citizens' perception}

During the FGDs, the interviews were facilitated and guided by the researcher and invited to discuss freely issues relating to the local governmental activities. As our aim is to explore the possibility to support local governmental decision making, we will create the map to be able to focus on the most prioritised areas to decide the holistic policy menu which could make their citizens satisfied with their local governments. Cognitive map has been utilised by researchers as one of the idealistic method to visualise the perceptions of interviewees to explore the best option in responding to the research questions $[14,77]$.

\section{$4 \quad$ Analysis and findings}

\subsection{FGDs exploring citizens' willingness to participate in policy designing}

From three FGDs with a variety of participants, there are quite a divers comments were collected.

\section{Disappointment for the lack of the opportunities to participate in governmental decision making}

The first category of the comments could be summarised that citizens are ready to contribute to their local governments but still they are not satisfied because of lacking of the opportunities to do so.

A: 'We would like to see more public policies are reflecting our views, however we are not feeling that our views are used by local governments which is a shame' (male, 50s).

B: 'The local government seems to have tried a lot to attract citizens to have more interest in their activities but still we are not sure how to contribute to our own government' (male, 40s).

C: 'It is nice for us to be contributors to the local governments, but being a citizen committee members are too difficult for our age as we have so many other thing to do such as growing our small kids' (female, 30s).

\section{The utilisation of the result of citizen survey}

The second category could be summarised as the result of citizen survey.

D: 'The local government has conducted several citizen surveys, what happened to the result, we are not sure...' (male, 40s).

E: 'It is common for the public sectors to conduct some kinds of surveys, but the conduct itself is now their aim, what happened to the result of those? We seldom hear about it. Strange!' (male, 30s). 
F:'How could they make the most of the data of the survey? The bureaucratic organisations usually fail to make the most of it!' (male, 60s).

\section{The self-awareness as tax payers}

G: 'Of course it is their duty and responsibility to make it accountable how and what they decide based on our survey data, as everything was paid by our tax' (male, 50s). $\mathrm{H}$ : 'As a tax payer, it is our responsibility to contribute in decision making of the local government, but it is not clear by which occasion and procedure we can do so....' (female, 30s).

\section{The barriers preventing citizens' support in decision making of local government}

Final category could be summarised as 'their perception of the barriers for the citizens to support governmental decision.

I: 'Silent majority. Not all of us would like to contribute to our own local government. The majority of the citizens are just sitting there, as free riders' (male, 50s)

$\mathrm{J}$ : 'The structure of the organization. It seems to be difficult for the government to share the views and opinions from us' (female, 60s).

$\mathrm{K}$ : 'The lack of communication between us. Some of the citizens are active and willing to support the government, however, the good pipe between us and the government is not robust enough to encourage our interaction towards the good collaboration to realise good policy menu' (male, 40s).

\section{The outcome of FGDs}

As overviewed in the previous sections, citizens seem to have a doubt that their precious views through citizen survey is not utilised enough, although they are sincerely willing to contribute in supporting the governmental decision. Moreover, the result of the survey is not visualised clearly and feed backed to the citizens, which might affect their motivation in being active to support their government.

The outcome of the FGDs indicate that it is essential for the local government to feed back the result of the relevant survey to the citizens and in doing so, citizens' motivation to contribute to the local governmental activities could be enhanced and through this path the trust between citizens and governments could be nurtured which could build the good basis as a platform on which all of the stakeholders of the government could collaborate in designing ideal policy menu.

\subsection{Building a cognitive map based on text mining}

Following the FGDs, we now are going to the next stage to build a cognitive map using the result of citizen survey. To make the result visualised could be effective for enhancing the understanding level of the survey result among citizens, at the same time, it could be useful to evaluate the holistic views which policy activities are 
prioritised by citizens which could be a good material for the governmental decision making.

\section{Procedure}

To attain a cognitive map, we implement SPSS text analytics for survey version 4.0.1. There are several software available, but as an experimental basis, we decided to use this as we usually analyse the data quantitatively based on SPSS systems.

Figure 1 shows the process of data preparation on this system. We use 1204 comments from survey participants.

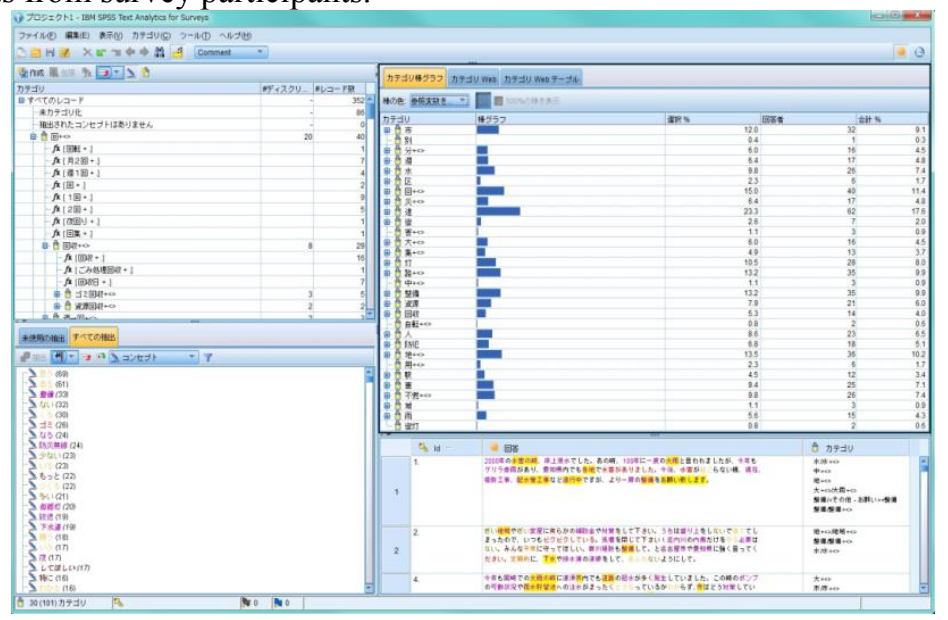

Fig. 1. Text mining procedure

\section{Setting categories}

Before starting text mining, we are required to set categories to analyse the dataset. Chart 2 shows the screenshot of the setting. In this case, we analyse all of the 'nouns', then categorise 'good/bad', 'satisfied/unsatisfied', 'bad/worrying/anxiety', 'please/ask', 'proposition/warn' and 'trouble/improvement'. SPSS text analytical protocol is eligible for the unique Japanese linguistic characteristics, hence we also check our analysis will consider Japanese language context as well. 


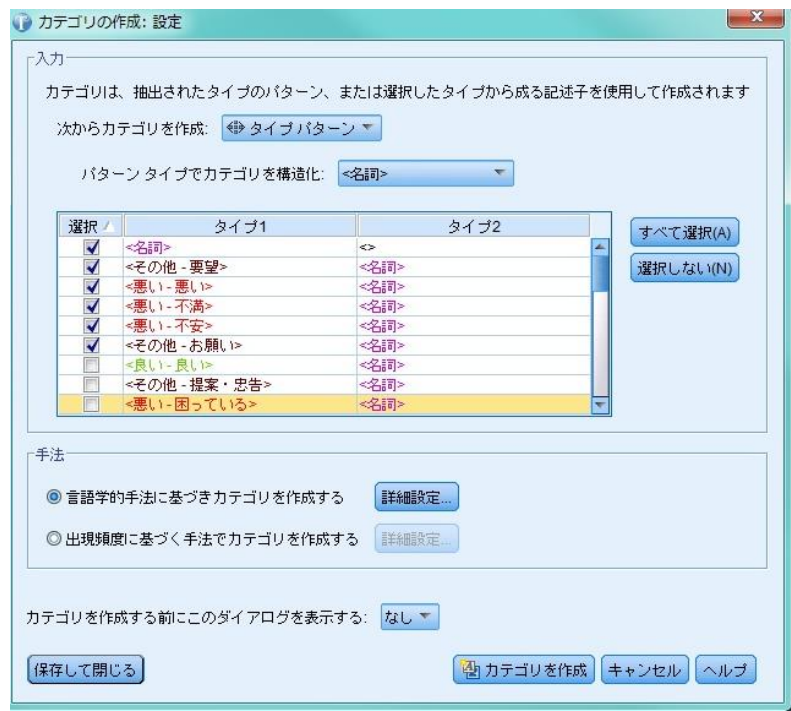

Fig. 2. Categories setting

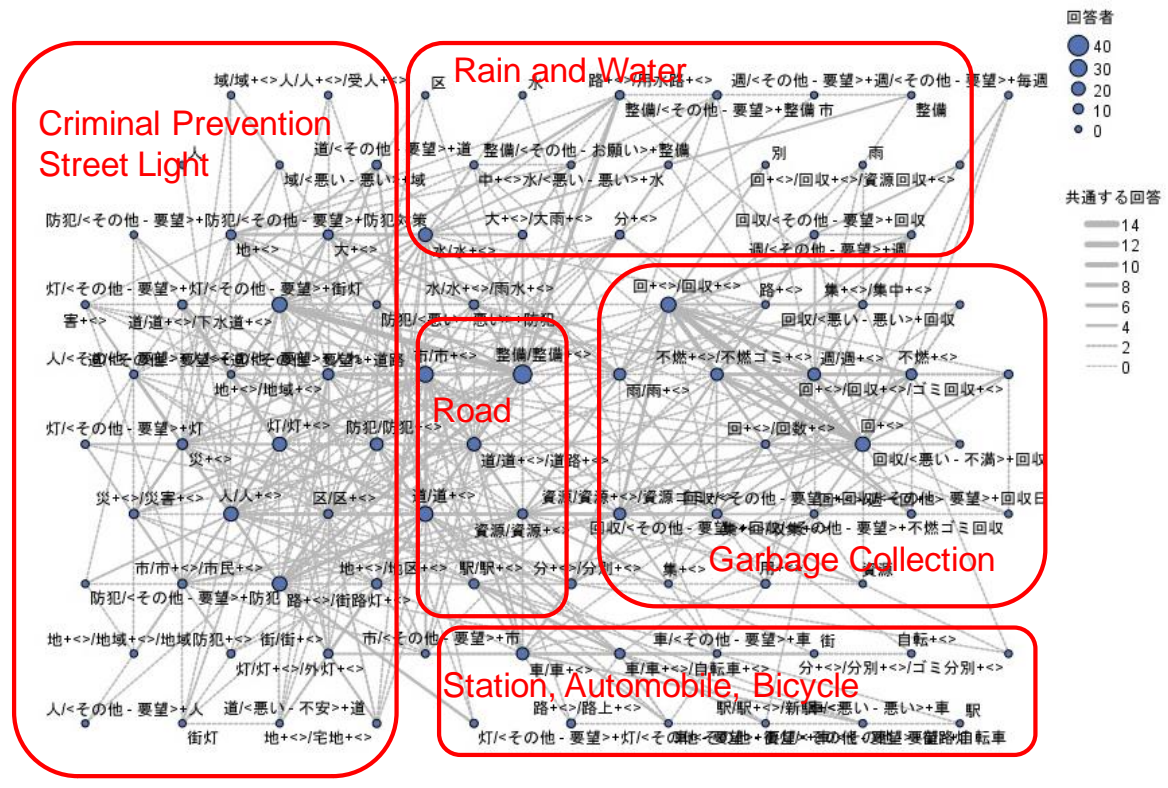

Fig. 3. Grid and categorization

\subsection{Grid and categorisation}

Following this preparation, we attain grid layout of the key words and Figure 3 shows our categorisations with red circles. Grid layout indicates which words are close and which are frequently appeared in the comments of the survey participants. 
Based on the information of this grid layout, we categorise five groups as the policy menu which citizens perceive important to implement; 'security on the street at night', 'water and flooding prevention', 'road construction', 'collect the rubbish' and 'parking lots in the station'.

\section{Discussion and Conclusion}

\subsection{Discussion}

From our analyses of the first phase as FGDs of activated participants, there are several key words were depicted. Among those, we could estimate those who are willing to contribute to the local government have noticed some barriers in doing so because of the bureaucratic oraganisation, and also they perceive the lack of instruments by which their views are reflected in policy selection by their local government. Moreover they appreciate governmental attitudes to implement citizens' views via conducting citizen survey, however, they seem to be frustrated with the vague outcome what and how those views were utilized in the governmental actions. Hence our first phase of research can conclude that it is required for the local government to introduce some solid procedure to depict essence from the survey result and enhance communication with conductor and participants for the citizen survey.

Bearing this in mind, we built a cognitive map indicating which categories of policy actions are perceived by citizens as prioritized fields of policy menu which is shown as the figure 3 . As it shows, there are five areas which citizens prioritised, all of those are quite daily-life based issues, quite different scenery was attained compared to the outcome of previous literature discussion which is an interesting finding. In our section 2, we surveyed the relevant literature review to present some essential fields such as indicate some health and welfare policies and city beautification, however we found out other elements such as security on the streets at night, improvement of roads and parking lots of stations and prevention of flooding. In other words, citizens seem to perceive more importance on the public activities in the basic security related fields.

Indeed, social capital implication which prevailed in Cabinet Office Initiatives, Japan [79], nurturing community bonding and commitment has been discussing quite a long time since then as social capital could be helpful for building sustainable communities, however, perhaps this kind of 'social capital' debate is applicable only when basic infrastructure is solid to enable citizens feel secured in the community. Moreover, even elderly people would prefer to prioritise social infrastructure improvement rather than health and welfare policy, which could imply that we should once again re-consider the layout of policy agenda in the local community $[25,26$, 34]. To be able to present this ironical gap with theoretical discussion and reality of citizens' perception could be discovered by building cognitive map based on the citizen survey result, which indicates its usefulness and applicability in supporting local governmental decision making. 


\subsection{Limitations and recommendations}

The content of this study could contribute in providing the feasible supporting system for the local governmental decision making. Especially considering the tight budget circumstances, it is essential for them to implement effective system to conduct reasonable policy selection. However, this research should be deepened with a specific scope how the local governments plan and conduct effective citizen survey in the first place. Otherwise, we can obtain the robust origin for our cognitive mapping to depict their perceptions useful for them to analyse and explore their real views in the community governance context. In addition, how to analyse the relations among policy menu and achievable political goals 'how to realise citizen satisfaction' is still on our research agenda.

In reality, when implementing the policy menu, the budget limitations and other political issues exist always there, which should be discussed at the same time. In this study, only several policy fields are discussed with relevant literature, however many other issues are also interrelated with the real policy actions holistically, hence it should be our social researchers' responsibility to support local governmental practices with provision of feasible decision support systems with trial and error experiments based on the cooperation and collaboration with stakeholders which could contribute to the local communities in the end. Through these actions, the real sustainable relationships among local government and citizens could be achieved via enhancing citizen satisfaction and their commitment, by finding antecedent factors realising their satisfaction and trust towards their local government $[5,20,21]$. The authors would like to continue the relevant study so that we could produce more robust proposal in supporting the governmental decision making in choosing the best combination of prioritised policy menu.

As another limitation, in this project, we could not enhance our research scope to policy makers perceptions of whose opinions and views are critical in integrating in the holistic proposal of this data analysis. We acknowledge this limitation as essential to be mitigated as they are responsible for policy making in most representative democracies.

Moreover, the informants of this dataset are only over $30+$ years of age, which might have caused an imbalance of the data variance. Hence when we build a proposal of this procedure to the practices in the reality, we should conduct another data collection and test of the usefulness of this software based on a broader and better balanced age bands of respondents.

\section{References}

1. National Land Council, Japan (2011) "Long-term View of the Country" Interim Daft Outline http://www.mlit.go.jp/common/000135837.pdf 【26/10/2015 Accessed】

2. Ministry of Land, Infrastructure, Transport and Tourism (2013) "White Paper on Land, Infrastructure and Transport in Japan 2012” http://www.mlit.go.jp/english/whitepaper/2011.pdf 【16/10/2015 Accessed】 
3. Watson, D. J., Juster, R. J. and Johnson, G. W.: Institutionalized use of citizen surveys in the budgetary and policy-making processes: a small city case study. Public Administration Review, 51, 232-239 (1991)

4. Herian, M. N. and Tomkins, A. J.: Citizen Satisfaction Survey Data: A Mode Comparison of the Derived Importance-Performance Approach. American Review of Public Administration, 42 (1), 66-86 (2012)

5. Kelly, J. M. and Swindell, D.: A Multiple-Indicator Approach to Municipal Service Evaluation: Correlating Performance Measurement and Citizen Satisfaction across Jurisdictions. Public Administration Review, 62 (5), 610-621 (2002)

6. Brown, T.: Coercion versus Choice: Citizen Evaluations of Public Service Quality across Methods of Consumption. Public Administration Review, 67 (3), 559-572 (2007)

7. Dowding, K. and John, P.: Voice and choice in health care in England: understanding citizen responses to dissatisfaction. Public Administration, 89 (4), 1403-1418 (2011)

8. Greasley, S. and John, P.: Does Stronger Political Leadership Have a Performance Payoff? Citizen Satisfaction in the Reform of Subcentral Governments in England. JOURNAL OF PUBLIC ADMINISTRATION RESEARCH AND THEORY, 21 (2), 239-256 (2011)

9. Kelly, J. M.: The Dilemma of the Unsatisfied Customer in a Market Model of Public Administration. Public Administration Review, 65 (1), 76-84 (2005)

10. Poister, T. H. and Henry, G. T.: Citizen ratings of public and private service quality: A comparative perspective. Public Administration Review, 54 (2), 155 (1994)

11. Morgeson, F. V.: Expectations, Disconfirmation, and Citizen Satisfaction with the US Federal Government: Testing and Expanding the Model. Journal of Public Administration Research \& Theory, 23 (2), 289-305 (2013)

12. Lourenco, R. P. and Costa, J. P.: Incorporating citizens' views in local policy decision making processes. DECISION SUPPORT SYSTEMS, 43 (4), 1499-1511 (2007)

13. Ranerup, A.: Decision Support Systems for Public Policy Implementation: The Case of Pension Reform. Social Science Computer Review, 26 (4), 428-445 (2008)

14. Moreno-Jiménez, J. M., Cardeñosa, J. and Gallardo, C.: Arguments That Support Decisions in e-Cognocracy: A Qualitative Approach Based on Text Mining Techniques. Visioning \& Engineering the Knowledge Society. a Web Science Perspective, 427 (2009)

15. Rao, G. K. and Dey, S.: Decision Support for e-Governance: A Text Mining Approach (2011a)

16. Rao, G. K. and Dey, S.: Text mining based decision support system (TMbDSS) for Egovernance: A roadmap for India [Conference Paper]. Vol. 198 CCIS (2011b)

17. Mostafa, M. M. and El-Masry, A. A.: Citizens as consumers: Profiling e-government services' users in Egypt via data mining techniques. International Journal of Information Management, 33 (4), 627-641 (2013)

18. Fleming, L. E., Haines, A., Golding, B., Kessel, A., Cichowska, A., Sabel, C. E., Depledge, M. H., Sarran, C., Osborne, N. J., Whitmore, C., Cocksedge, N. and Bloomfield, D.: Data mashups: potential contribution to decision support on climate change and health. International Journal Of Environmental Research And Public Health, 11 (2), 1725-1746 (2014)

19. De Cnudde, S. and Martens, D.: Loyal to your city? A data mining analysis of a public service loyalty program. Decision Support Systems, 73, 74-84 (2015)

20. Stipak, B.: Citizen Satisfaction With Urban Services: Potential Misuse as a Performance Indicator. Public Administration Review, 39 (1) (1979)

21. Van Ryzin, G. G.: Testing the Expectancy Disconfirmation Model of Citizen Satisfaction with Local Government. Journal of Public Administration Research \& Theory, 16 (4), 599611 (2006)

22. Crowley, Kate, and Brian Coffey: New Governance, Green Planning and Sustainability: Tasmania Together and Growing Victoria Together. Australian Journal of Public Administration 66 (1):23-37 (2007) 
23. Bridgman, P., and G. Davis, G.. The Australian Policy Handbook. 2nd edition, Sydney: Allen and Unwin (2000)

24. Irimia, Horia: REGIONAL ECONOMY AND PUBLIC ADMINISTRATION. Annals of Eftimie Murgu University Resita, Fascicle II, Economic Studies:199-202 (2011)

25. Cordes, Sam, John Allen, Richard C. Bishop, Gary D. Lynne, Lindon J. Robison, Vernon D. Ryan, and Ron Shaffer: Social Capital, Attachment Value, and Rural Development: A Conceptual Framework and Application of Contingent Valuation. American Journal of Agricultural Economics 85 (5):1201-1207 (2003)

26. Crawford, Pat, Zenia Kotval, Warren Rauhe, and Zeenat Kotval: Social capital development in participatory community planning and design. TPR: Town Planning Review 79 (5):533$553(2008)$

27. Smith, G. R.: Achieving Sustainability: Exploring Links Between Sustainability Indicators and Public Involvement for Rural Communities. Landscape Journal, 19 (1/2), 179 (2000)

28. Yang, K. and Callahan, K.: Citizen Involvement Efforts and Bureaucratic Responsiveness: Participatory Values, Stakeholder Pressures, and Administrative Practicality. Public Administration Review, 67 (2), 249-264 (2007)

29. Arvind, G. R.: The State, Local Community and Participatory Governance Practices: Prospects of Change. Proceedings of World Academy of Science: Engineering \& Technology, 46, 697-708 (2008)

30. Cooper, C. A. c. e. w. e., Knotts, H. G. g. e. w. e. and Brennan, K. M. k. w. e.: The Importance of Trust in Government for Public Administration: The Case of Zoning. Public Administration Review, 68 (3), 459-468 (2008)

31. McIntyre, T. and Halsall, J.: Community governance and local decision making: Paper presented to the 'Diversity and Convergence: Planning in a World of Change' Conference. Local Economy (Sage Publications, Ltd.), 26 (4), 269 (2011)

32. Creighton, J. L.: The public participation handbook : making better decisions through citizen involvement / James L. Creighton [Bibliographies Handbooks Non-fiction]. San Francisco : Jossey-Bass, c2005. 1st ed (2005)

33. Robison, Lindon J., and Jan L. Flora: The Social Capital Paradigm: Bridging across Disciplines (Paul Wilson, University of Arizona, presiding) The Social Capital Paradigm: Bridging across Disciplines. American Journal of Agricultural Economics 85 (5):1187$1193(2003)$

34. Julian, David A., and Ross, Melissa: Strengthening Infrastructure and Implementing Functions to Support Collaborative Community Problem Solving. Journal of Planning Literature 28 (2):124-134 (2013)

35. Yoshitake, Tetsunobu, and Chikashi Deguchi: Social capital development in a rural community based on exchange management with outsiders. TPR: Town Planning Review 79 (4):427-462 (2008)

36. McShane, I.: Social Value and the Management of Community Infrastructure. Australian Journal of Public Administration, 65 (4), 82-96 (2006)

37. Bedford, Tracey, Judy Clark, and Carolyn Harrison: Limits to new public participation practices in local land use planning. TPR: Town Planning Review 73 (3):311 (2002)

38. Noworól, Aleksander: Social Capital and Multilevel Territorial Management. The case of Poland. Kapitał społeczny a wielopasmowe zarządzanie terytorialne. Przypadek Polski. 2:99-110 (2011)

39. Olsson, K: Citizen input in urban heritage management and planning. TPR: Town Planning Review 79 (4):371-394 (2008)

40. Martin, S. A. and Morehead, E.: Regional Indicators as Civic Governance: Using Measurement to Identify and Act Upon Community Priorities. National Civic Review, 102 (1), 33-42 (2013) 
41. Warburton, Jeni, Jo-Anne Everingham, Michael Cuthill, and Helen Bartlett: Achieving Effective Collaborations to Help Communities Age Well. Australian Journal of Public Administration 67 (4):470-482 (2008)

42. Williams, Philippa, and Pocock, Barbara: Building 'community' for different stages of life: physical and social infrastructure in master planned communities. Community, Work \& Family 13 (1):71-87 (2010)

43. Barnes, M.: Users as Citizens: Collective Action and the Local Governance of Welfare. Social Policy \& Administration, 33 (1), 73-90 (1999)

44. Caldwell, K., Saib, M. and Coleman, K.: The ageing population: challenges for policy and practice. Diversity in Health \& Social Care, 5 (1), 11-18 (2008)

45. Corbett, S.: Review of The big society debate: A new agenda for social welfare? Critical Social Policy, 33 (1), 185-187 (2013)

46. Mitchell, Shannon M., and Shortell, Stephen M.: The Governance and Management of Effective Community Health Partnerships: A Typology for Research, Policy, and Practice. The Milbank Quarterly (2):241 (2000)

47. Driedger, S. M.: Creating shared realities through communication: exploring the agendabuilding role of the media and its sources in the E. coli contamination of a Canadian public drinking water supply. Journal of Risk Research, 11 (1/2), 23-40 (2008)

48. Jorna, F.: Going Dutch. Informatisation and Citizen-government Relations. Going dutch, lnformatisierung und Bürger-government relations., 2014 (1), 21-30 (2014)

49. Patrick, R.; Roseland, M: Developing sustainability indicators to improve community access to public transit in rural residential areas. Journal of Rural and Community Development; 1(1), Brandon:Department of Rural Development, Brandon University, 1-17 (2005)

50. Dabinett, Gordon: Realising regeneration benefits from urban infrastructure investment: lessons from Sheffield in the 1990s. TPR: Town Planning Review 69 (2):171 (1998)

51. Marshall, Tim: Reforming the process for infrastructure planning in the UK/England 19902010. TPR: Town Planning Review 82 (4):441-467 (2011)

52. Jakaitis, J. and Stauskis, G.: Facilitating Sustainable Development of Urban Landscape by Involvement of Local Territorial Communities in Vilnius City. Architecture \& Urban Planning, (5), 105-111 (2011)

53. Lemert, C.: Review of 'Genealogies of citizenship: Markets, statelessness, and the right to have rights'. American Journal of Sociology, 117 (3), 989-991 (2011)

54. Shigeoka, T.: The Improvement of Rural Life Environment and the Reconstruction toward Beautiful Rural Community in Japan. Journal of Rural Studies, 6 (2), 36-47 (2000)

55. Bookman, S. and Woolford, A.: Policing (by) the urban brand: defining order in Winnipeg's Exchange District. Social \& Cultural Geography, 14 (3), 300-317 (2013)

56. Taylor, D. E.: Minority Environmental Activism in Britain: From Brixton to the Lake District. Qualitative Sociology, 16 (3), 263 (1993)

57. Fransico, J. P. S.: Are the Rich Willing to Pay for Beautiful Cities?: Income Effects on the Willingness to Pay for Aesthetic Improvements. Australasian Journal of Regional Studies, 16 (2), 233 (2010)

58. Kennedy, C.: The City of 2050 - An Age-Friendly, Vibrant, Intergenerational Community. Generations, 34 (3), 70-75 76p (2010)

59. Ghahramanpouri, A., Abdullah, A. S., Sedaghatnia, S. and Lamit, H.: Urban Social Sustainability Contributing Factors in Kuala Lumpur Streets. Procedia - Social and Behavioral Sciences, 201, 368-376 (2015)

60. Daskon, C. and McGregor, A.: Cultural Capital and Sustainable Livelihoods in Sri Lanka's Rural Villages: Towards Culturally Aware Development. Journal of Development Studies, 48 (4), 549-563 (2012) 
61. Harun, N. Z., Zakariya, K., Mansor, M. and Zakaria, K.: Determining Attributes of Urban Plaza for Social Sustainability. Procedia - Social and Behavioral Sciences, 153, 606-615 (2014)

62. Nzeadibe, T. C. and Mbah, P. O.: Beyond urban vulnerability: interrogating the social sustainability of a livelihood in the informal economy of Nigerian cities. Review of African Political Economy, 42 (144), 279-298 (2015)

63. Glazer, N.: Shanghai surprise - The most vibrant city in the world isn't New York. NEW REPUBLIC, 238 (1), 12-13 (2008)

64. Baker, P.: LONDON LORE The legends and traditions of the world's most vibrant city. TLS-THE TIMES LITERARY SUPPLEMENT, (5518), 28-28 (2009)

65. Rizzi, P. and Dioli, I.: Strategic planning, place marketing and city branding: The Italian case. Journal of Town \& City Management, 1 (3), 300-317 (2010)

66. Macleod, G. and Johnstone, C.: Stretching Urban Renaissance: Privatizing Space, Civilizing Place, Summoning 'Community'. International Journal of Urban \& Regional Research, 36 (1), 1-28 (2012)

67. Wetzstein, S.: Globalising Economic Governance, Political Projects, and Spatial Imaginaries: Insights from Four Australasian1 Cities Globalising Economic Governance, Political Projects, and Spatial Imaginaries: Insights from Four Australasian Cities. Geographical Research, 51 (1), 71-84 (2013)

68. Anderson, T.: City profile: Malmo: A city in transition. Cities, 39, 10-20 (2014)

69. Ardichvili, A., Cardozo, R. and Ray, S.: A theory of entrepreneurial opportunity identification and development. Journal of Business Venturing, 18, 105-123 (2003)

70. Garcia, G. A. and Gaytan, E. A.: Trust in Spanish governments: Antecedents and consequences. Economic Analysis and Policy, 43 (2), 177 (2013)

71. Myung, J.: Citizen Participation, Trust, and Literacy on Government Legitimacy: The Case of Environmental Governance. Journal of Social Change, 5 (1), 11-25 (2013)

72. Smith, J. W., Leahy, J. E., Anderson, D. H. and Davenport, M. A., Community/agency trust and public involvement in resource planning. Society \& Natural Resources, 26 (4), 452-471 (2013)

73. Herian, M. N., Shank, N. C. and Abdel-Monem, T. L.: Trust in government and support for governmental regulation: the case of electronic health records. HEALTH EXPECTATIONS, 17 (6), 784-794 (2014)

74. Van Ryzin, G. G., Muzzio, D., Immerwahr, S., Gulick, L. and Martinez, E.: Drivers and Consequences of Citizen Satisfaction: An Application of the American Customer Satisfaction Index Model to New York City. Public Administration Review, 64 (3), 331341 (2004)

75. Kathi, P. C. and Cooper, T. L.: Connecting Neighborhood Councils and City Agencies: Trust Building through the Learning and Design Forum Process. Journal of Public Affairs Education, 13 (3/4), 617-630 (2007)

76. Geren, Kenneth J.: 'New Governance, Green Planning \& Sustainability: Reviewing Tasmania Together and Growing Victoria Together' Australian Journal of Public Administration 66(1), 23-37 (1988).

77. Hines, T.: An evaluation of two qualitative methods (focus group interviews and cognitive maps) for conducting research into entrepreneurial decision making. Qualitative Market Research: An International Journal, 3 (1), 7-16 (2000)

78. Corbin, Juliet and Strauss, Anselm: Grounded theory research: Procedures, Canons, and Evaluative criteria. Qualitative Sociology, 13(1), 3-21 (1990)

79. Cabinet Office, Japan. Social Capital: Seeking a virtuous cycle of the rich human relations and civil activities (2003)

http://www5.cao.go.jp/seikatsu/whitepaper/h19/01_honpen/index.html【16/10/2015

Accessed] 